\title{
BMJ Open Outcomes of antiretroviral treatment in HIV-infected adults: a dynamic and observational cohort study in Shenzhen, China, 2003-2014
}

\author{
Peng Huang, ${ }^{1}$ Jingguang Tan, ${ }^{2}$ Wenzhe Ma, ${ }^{1}$ Hui Zheng, ${ }^{1}$ Yan Lu, ${ }^{2}$ Ning Wang, ${ }^{3}$ \\ Zhihang Peng, ${ }^{1}$ Rongbin $\mathrm{Yu}^{1}$
}

To cite: Huang $\mathrm{P}$, Tan J, Ma W, et al. Outcomes of antiretroviral treatment in HIV-infected adults: a dynamic and observational cohort study in Shenzhen, China, 2003-2014. BMJ Open 2015;5:e007508. doi:10.1136/bmjopen-2014007508

\section{- Prepublication history} and additional material is available. To view please visit the journal (http://dx.doi.org/ 10.1136/bmjopen-2014007508).

$\mathrm{PH}$ and JT contributed equally to this work.

Received 22 December 2014 Revised 12 April 2015 Accepted 15 April 2015

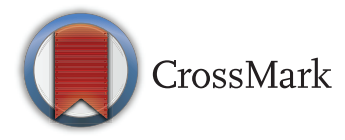

\footnotetext{
${ }^{1}$ Department of Epidemiology and Biostatistics, School of Public Health, Nanjing Medical University, Nanjing, China

2Department of STDs/AIDS Prevention and Control, Shenzhen Center for Disease Control and Prevention, Shenzhen, China ${ }^{3}$ National Center for AIDS/ STD Control and Prevention, Chinese Center for Disease Control and Prevention, Beijing, China
}

Correspondence to Dr Zhihang Peng; zhihangpeng@njmu.edu.cn

\section{ABSTRACT}

Objectives: To report 10-year outcomes of virological and immunological treatment failure rates and risk factors.

Design: Prospective cohort study.

Setting: Shenzhen, China.

Participants: 2172 HIV-positive adults in the national treatment database of Shenzhen from December 2003 to January 2014.

Intervention: Antiretroviral therapy according to the Chinese national treatment guidelines.

Outcome measures: Virological and immunological treatment failure rates.

Results: Of the 3099 patients surveyed, 2172 (70.1\%) were included in the study. The median age was 33 years; $78.2 \%$ were male and $51.8 \%$ were infected through heterosexual contact. The median follow-up time was 31 months (IQR, 26-38). A total of 81 (3.7\%) patients died, whereas $292(13.4 \%)$ and 400 $(18.4 \%)$ patients experienced virological and immunological failures, respectively. Adjusted Cox regression analysis indicated that baseline viral load ( $\mathrm{HR}=2.19,95 \% \mathrm{Cl} 1.52$ to 4.48 for patients with a baseline viral load greater than or equal to 1000000 copies $/ \mathrm{mL}$ compared to those with less than 10000 copies $/ \mathrm{mL}$ ) and WHO stage (HR=4.16, 95\% $\mathrm{Cl} 2.01$ to 10.57 for patients in WHO stage IV compared with those in stage I) were significantly associated with virological failure. The strongest risk factors for immunological treatment failure were a low $\mathrm{CD} 4$ cell count (HR=0.46, 95\% Cl 0.32 to 0.66 for patients with CD4 cell counts of 50-99 cells $/ \mathrm{mm}^{3}$ compared to those with less than $50 \mathrm{cell} / \mathrm{s} / \mathrm{mm}^{3}$ ) and higher baseline WHO stage at treatment initiation (HR=2.15, $95 \% \mathrm{Cl}$ 1.38 to 3.34 for patients in WHO stage IV compared to those in stage I).

Conclusions: Sustained virological and immunological outcomes show that patients have responded positively to long-term antiretroviral treatment with low mortality. This 10 -year data study provides important information for clinicians and policymakers in the region as they begin to evaluate and plan for the future needs of their own rapidly expanding programmes.

\section{Strengths and limitations of this study}

- This study had large sample sizes and 10 year durations of follow-up.

- This was the first study to assess outcomes of China's National Free Antiretroviral Treatment Programme in Shenzhen.

- This observational study had potential inherent biases, such as follow-up bias.

- Missing data existed in a cohort study.

- Medication adherence was hardly measured.

\section{INTRODUCTION}

In China, the number of people infected with HIV is 740000 in estimation. ${ }^{1}$ Among these, a cumulative 436817 people living with HIV/ AIDS had been identified up to December 2013, including 173825 people with AIDS. ${ }^{2}$ Since the China National Free Antiretroviral Treatment Programme (NFATP) was established in 2003, the remarkable acceleration in treatment has been obvious. ${ }^{3}{ }^{4}$ By December 2013, more than 278000 people have received first-line highly active antiretroviral therapy (HAART). Along with the increasing treatment coverage, overall mortality rates have fallen from 39.3 deaths per 100 person-years in 2000 to 14.2 deaths per 100 person-years in 2009. ${ }^{5}$ All HIV-infected individuals who meet the national treatment criteria are eligible to receive treatment, and treatment has been implemented in all 31 provinces, autonomous regions and municipalities in China. ${ }^{78}$

The limitations of previous studies reporting the effects of HAART in developing countries were the relatively small sample sizes or short durations of follow-up. ${ }^{9-16}$ Fortunately, our study reports the 10-year outcomes of virological and immunological treatment failure rates and their associated risk factors for all adult patients enrolled in the NFATP in Shenzhen. 


\section{METHODS}

\section{Patients and treatment regimens}

This study was approved by the Institutional Review Board of the Nanjing Medical University. All patients were registered in the NFATP of Shenzhen and the observational database from December 2003 to January 2014. In accordance with Chinese policy, all HIV-positive patients who met the national treatment guidelines of a CD4 cell count less than 350 cells $/ \mathrm{mm}^{3}\left(<200\right.$ cells $/ \mathrm{mm}^{3}$ before 2008) or WHO stage III or IV disease were eligible to receive antiretroviral treatment (ART). ${ }^{17}{ }^{18}$ Excluded patients were not previously naive to ART, had a duration of ART lasting less than 6 months, were younger than 18 years at treatment initiation, had not initially received the appropriate triple therapy, or had missing initial treatment dates. To evaluate the outcomes, patients without baseline CD4 cell and plasma viral load or without at least one follow-up CD4 cell and plasma viral load were also excluded.

Treatment procedures were conducted in accordance with the Chinese National Free HIV Antiretroviral Treatment Guidelines. ${ }^{17}{ }^{19}$ The first-line regimen was a combination therapy of two nucleoside reverse transcriptase inhibitors and one non-nucleoside reverse transcriptase inhibitor, which consisted of lamivudine (3TC), zidovudine (AZT), stavudine (d4T), didanosine (ddI), tenofovir (TDF), nevirapine (NVP) and efavirenz (EFV). After the national antiretroviral treatment guidelines were updated in 2008, ART failure participants were generally switched to a second-line regimen including TDF, 3TC and lopinavir/ritonavir (LPV/r).

\section{Patient visits and data collection}

After treatment initiation, follow-up visits were scheduled at half, 1, 2 and 3 months, and once every 3 months thereafter. Risk factors consisted of demographic characteristics, laboratory results and current symptoms. The following baseline laboratory tests were carried out: chemistry, haematology, CD4 cell count, plasma HIV RNA level, hepatitis B surface antigen and hepatitis C antibody. Survival time was defined from the date of ART initiation until death or the date of the last follow-up. Moreover, the patient missing four consecutive follow-up appointments was identified lost to follow-up and the termination date when the treatment termination form was completed was regarded as the date of the last follow-up.

\section{Definitions}

For the analysis of virological and immunological treatment failure and $\mathrm{CD} 4$ cell count response, we included viral load and CD4 cell count only from patients with one or more follow-ups. We defined immunological treatment failure using the following WHO criteria: CD4 cell count less than 100 cells $/ \mathrm{mm}^{3}$ after receiving treatment for 6 months, CD4 cell count at or below pretreatment level after receiving treatment for 6 months, or $\mathrm{CD} 4$ cell count less than $50 \%$ of peak on-treatment level. ${ }^{20}$ We considered treatment as having failed for patients who met any of these criteria. Virological failure was defined as a viral load of 1000 copies $/ \mathrm{mL} .^{20}$ Time to failure was the time from treatment initiation date to the date when the patient met the failure criteria.

\section{Statistical analysis}

The Mann-Whitney test defined the significant continuous variables whose distributions were not normal. The Pearson $\chi^{2}$ statistic tested dichotomous and categorical variables. For the assumption of proportionality, the Log-rank test was applied to test the survival rate between groups. The Cox model assessed the HRs of potential risk factors. Multivariate Cox models were constructed by clinically significant variables. The above analysis was completed by Stata V.12.0 (StataCorp, College Station, Texas, USA). All hypothesis testing was twosided, with an $\alpha$ level of 0.05 .

\section{RESULTS}

Of the 3099 patients with AIDS/HIV from the NFATP database of Shenzhen in January 2014, 927 were excluded (see online supplementary figure S1). Of the remaining patients, 81 died $(78.8 \%$ of these deaths were AIDS related). The median follow-up time was 31 months (IQR, 26-38), with a median of 15 follow-up visits (IQR, 11-20). The median age was 33 years; $78.2 \%$ of patients were male, $49.3 \%$ were married, $82.8 \%$ received a middle school level of education, $24.8 \%$ were engaged in commercial service and $51.8 \%$ were infected through heterosexual contact (table 1). The baseline median CD4 cell count was 168 cells $/ \mathrm{mm}^{3}$ (IQR, 71-242), and $19.5 \%$ of patient cell counts were less than 50 cells $/ \mathrm{mm}^{3}$. The median baseline plasma viral load was 162000 copies/mL (IQR, 42 200-467 750), and $62.5 \%$ of the patients' viral load were 100000 cells $/ \mathrm{mm}^{3}$ or above. The baseline median haemoglobin, alanine aminotransferase (ALT) and aspartate transaminase (AST) were $140 \mathrm{~g} / \mathrm{L}, 22 \mathrm{U} / \mathrm{L}$ and $24 \mathrm{U} / \mathrm{L}$, respectively. At baseline, $33.4 \%$ of patients were in WHO clinical stage IV, 13.2\% were hepatitis B virus (HBV) positive and $4.8 \%$ were hepatitis $\mathrm{C}$ virus (HCV) positive.

Virological and immunological treatment failure rates evaluated the outcomes. A total of 292 (13.4\%; 95\% CI $12 \%$ to $15 \%$ ) patients met the definition for virological treatment failure. The median follow-up plasma HIV RNA level count was 8 (IQR, 4-11). Patients with virological failure were generally those with higher baseline viral loads or higher baseline WHO stages $(p<0.001$; table 1). The cumulative proportion of patients experiencing virological failure increased over time from $6.7 \%$ at 6 months to $31.5 \%$ at 96 months (see online supplementary figure S2). Adjusted Cox regression showed that those infected through intravenous drug use were more likely to experience virological failure (HR, 2.09; $95 \%$ CI 1.05 to $4.17 ; \mathrm{p}<0.001)$ compared with those infected by heterosexual contact. Those with a baseline 
Table 1 Baseline patient characteristics stratified by virological and immunological failure

\begin{tabular}{|c|c|c|c|c|c|c|c|}
\hline Characteristic & Total $(n=2172)$ & $\begin{array}{l}\text { Virological } \\
\text { success }\end{array}$ & Virological failure & p Value & $\begin{array}{l}\text { Immunological } \\
\text { success }\end{array}$ & $\begin{array}{l}\text { Immunological } \\
\text { failure }\end{array}$ & p Value \\
\hline Median age (IQR), years & $33(28-40)$ & $33(28-40)$ & $33(29-40)$ & 0.667 & $33(28-40)$ & $34(29-42)$ & 0.013 \\
\hline Male, n (\%) & $1699(78.2)$ & $1474(78.4)$ & $225(77.1)$ & 0.594 & $1392(78.6)$ & $307(76.8)$ & 0.422 \\
\hline Married, n (\%) & $1070(49.3)$ & $913(48.6)$ & $157(53.8)$ & 0.002 & $853(48.1)$ & 217 (54.3) & 0.031 \\
\hline $\mathrm{BMI} \geq 18.5\left(\mathrm{~kg} / \mathrm{m}^{2}\right), \mathrm{n}(\%)$ & $1481(82.8)$ & 1335 (82.9) & $146(82.0)$ & 0.754 & $1258(83.6)$ & $223(78.3)$ & 0.032 \\
\hline Education: middle school, $\mathrm{n}(\%)$ & $1362(62.7)$ & $1174(62.5)$ & $188(64.4)$ & 0.558 & $1107(62.8)$ & $255(63.8)$ & 0.647 \\
\hline Occupation: commercial service, n (\%) & $525(24.8)$ & $452(24.6)$ & $73(25.9$ & 0.657 & $450(26.0)$ & $75(19.4)$ & 0.013 \\
\hline Infection route: heterosexual, $\mathrm{n}(\%)$ & $1125(51.8)$ & $978(52.1)$ & $147(50.3)$ & 0.615 & $906(51.1)$ & $219(54.8)$ & 0.203 \\
\hline $\begin{array}{l}\text { Median baseline CD4 cell count (IQR), } \\
\text { cells } / \mathrm{mm}^{3}\end{array}$ & $168(71-242)$ & $169(71-243)$ & $167(70-242)$ & 0.542 & $172(74-245)$ & $135(31-226.5)$ & $<0.001$ \\
\hline CD4 cell count $<50$ cells $/ \mathrm{mm}^{3}, \mathrm{n}(\%)$ & $423(19.5)$ & $362(19.3)$ & $61(20.9)$ & 0.525 & $287(16.2)$ & $136(34.0)$ & $<0.001$ \\
\hline $\begin{array}{l}\text { Median baseline viral load (IQR), } \\
\text { copies/mL }\end{array}$ & $\begin{array}{l}162000 \\
(42200-467750)\end{array}$ & $\begin{array}{l}150500 \\
(39975-444000)\end{array}$ & $\begin{array}{l}252000 \\
(101000-779750)\end{array}$ & $<0.001$ & $\begin{array}{l}157000 \\
(43700-455000)\end{array}$ & $\begin{array}{l}175000 \\
(35600-591000)\end{array}$ & 0.278 \\
\hline Viral load $\geq 100000$ copies/mL, n (\%) & $1184(62.5)$ & $1032(61.0)$ & $153(75.4)$ & $<0.001$ & $978(62.1)$ & $206(64.6)$ & 0.447 \\
\hline Median haemoglobin level (IQR), g/L & $140(122-151)$ & $141(122-151)$ & $136(122-150)$ & 0.414 & $141(124-151)$ & $136(118-149)$ & 0.013 \\
\hline Median ALT level (IQR), U/L & $22(15-37)$ & $22(15-37)$ & $25(16-39)$ & 0.104 & $22(15-36)$ & $22(14-38)$ & 0.664 \\
\hline Median AST level (IQR), U/L & $24(20-32)$ & 24 (19-32) & $26(20-35)$ & 0.177 & $24(19-32)$ & $24(20-34)$ & 0.520 \\
\hline Baseline WHO stage IV, n (\%) & $726(33.4)$ & $579(30.8)$ & $147(50.3)$ & $<0.001$ & $553(31.2)$ & $173(43.3)$ & $<0.001$ \\
\hline Baseline AIDS status, n (\%) & $1556(73.4)$ & $1347(73.3)$ & $209(74.4)$ & 0.380 & $1273(73.5)$ & $283(73.1)$ & 0.466 \\
\hline HBV positive, n (\%) & $198(13.2)$ & $183(13.6)$ & $15(9.9)$ & 0.255 & $171(13.4)$ & $27(12.2)$ & 0.747 \\
\hline HCV positive, n (\%) & $72(4.8)$ & $70(5.2)$ & $2(1.3)$ & 0.028 & $52(4.1)$ & $20(8.9)$ & 0.004 \\
\hline Tuberculosis, $\mathrm{n}(\%)$ & $86(4.0)$ & $75(4.0)$ & $11(3.9)$ & 0.730 & $60(3.4)$ & $26(6.7)$ & 0.003 \\
\hline
\end{tabular}


viral load greater than or equal to 1000000 copies $/ \mathrm{mL}$ had an adjusted HR of 2.19 (95\% CI 1.52 to 4.48; $\mathrm{p}<0.001)$ compared with those with a viral load less than 10000 copies $/ \mathrm{mL}$ (table 2). Patients with WHO clinical stage IV had an adjusted HR of 4.16 (95\% CI 2.01 to $10.57 ; \mathrm{p}<0.001)$ compared with those with stage I. The cumulative percentage of patients who experienced virological treatment failure was indicated by the baseline viral load (figure 1A) and WHO clinical stage (figure 1B). The results indicated that higher baseline viral load and WHO clinical stages were both significant predictors of virological failure $(\log$-rank $\mathrm{p}<0.001)$.

To understand treatment outcomes further, we identified patients with at least one follow-up CD4 cell count and analysed their immunological treatment failure rates and $\mathrm{CD} 4$ cell count responses. The median follow-up periods for CD4 cell count was 11 months (IQR 5-17) and 23 months (IQR 15-29).

Of the 2172 patients, 400 (18.4\%; $95 \%$ CI $16.8 \%$ to $20.1 \%$ ) were immunological treatment failures. They were more likely to be older and to have lower baseline CD4 cell counts or higher baseline WHO stage $(\mathrm{p}<0.001 ;$ table 1$)$. The cumulative proportion of patients for whom treatment failed increased over time from $10.3 \%$ at 6 months to $35.7 \%$ at 96 months (see online supplementary figure S3). Adjusted Cox regression suggested that the strongest risk factors for immunological treatment failure were a low CD4 cell count and higher baseline WHO stage at treatment initiation. Those with CD4 cell counts of 50-99 cells $/ \mathrm{mm}^{3}$ had an adjusted HR of 0.46 (95\% CI 0.32 to 0.66 ; $\mathrm{p}<0.001)$ and those with CD4 cell counts of 100-199 cells $/ \mathrm{mm}^{3}$ had an adjusted HR of 0.53 (95\% CI 0.41 to $0.70 ; \mathrm{p}<0.001)$ compared to those with $\mathrm{CD} 4$ cell counts of less than 50 cells $/ \mathrm{mm}^{3}$ (table 2). Patients in WHO stage IV had an adjusted HR of 2.15 (95\% CI 1.38 to 3.34; $\mathrm{p}<0.001)$ compared to those in stage I. The cumulative percentage of patients who experienced immunological treatment failure was shown by the baseline CD4 cell count (figure 1C) and WHO clinical stage (figure 1D). Cumulative percentages of immunological failure at $6,12,36,60$ and 96 months were $15.8 \%$, $19 \%, 32 \%, 42.5 \%$ and $58.8 \%$ for patients with baseline CD4 cell counts of $<50$ cells $/ \mathrm{mm}^{3}$, and $9.5 \%, 13 \%$, $17.7 \%, \quad 17.7 \%$ and $17.7 \%$ for patients with baseline CD4 cell counts $\geq 200$ cells $/ \mathrm{mm}^{3}$. Meanwhile, the cumulative percentages of immunological failure for patients in baseline WHO clinical stage I at 6,12 , 36,60 and 96 months were $6 \%, 9.2 \%, 15 \%, 15 \%$ and $15 \%$ vs $14.3 \%, 17.5 \%, 28.6 \%, 33.1 \%$ and $50 \%$ for patients in stage IV. Advanced immunosuppression and WHO clinical stage were both significant predictors of immunological failure $(\log -\mathrm{rank} \mathrm{p}<0.001)$.

The mean CD4 cell count response over time demonstrated the contrast between the immunological treatment success and failure cohorts: CD4 cell counts in the immunological success group continued to increase over time, whereas counts in the immunological failure group rapidly increased to 315 cells $/ \mathrm{mm}^{3}$ at 36 months but stabilised at this level thereafter (figure 2A). The mean $\mathrm{CD} 4$ cell count for patients with baseline $\mathrm{CD} 4$ cell counts of greater than or equal to 200 cells $/ \mathrm{mm}^{3}$ increased to $395,435,407$ and 436 cells $/ \mathrm{mm}^{3}$ at 12,36 , 60 and 96 months, but patients with less than 50 cells $/ \mathrm{mm}^{3}$ peaked at 349 cells $/ \mathrm{mm}^{3}$ for the full period of observation (figure 2B).

\section{DISCUSSION}

The NFATP in China faces many difficulties and challenges, especially severe resource limitations. Efforts have been made to manage and treat such a large number of patients over a wide area, including monitoring $\mathrm{CD} 4$ cell counts and viral load, training rural healthcare workers and expanding HIV care and treatment. ${ }^{3}{ }^{3} 19$ In this study, 2172 previously ART-naive adult patients with AIDS/HIV undergoing treatment from December 2003 to January 2014 in Shenzhen are included to evaluate the outcomes of treatment. Most notably, the rates of immunological and virological treatment failure increased over time to more than $30 \%$ at 96 months in the absence of readily available second-line treatment options. However, an interesting phenomenon was that death information was available for only 81 patients, whose mortality rate was largely lower than $13 \%$, a result from a previous national study. ${ }^{12}$ The first reason was that the situation of 238 patients who withdrew or were lost to this follow-up was perhaps more serious than that of the included patients. Another reason was that of 905 patients excluded from the study, 56 died during the follow-up. This study may underestimated the mortality rate, and the related risk factors about death need to be analysed in further study.

In this study, immunological treatment outcomes illustrate increasing failure rates over time without wide second-line treatment options. Many studies of treatment outcomes bypass treatment failure rates and report only changes in CD4 cell count over time. ${ }^{21}$ The WHO criteria in defining immunological treatment failure can guarantee comparability with other cohorts; however, our results are still different from the national outcomes studied in 2009. ${ }^{12}$ The cumulative immunological failure rate nationwide was approximately $50 \%$ at 5 years, which was much higher than ours. One vital reason may be that in the economically advanced city of Shenzhen, patient demographics such as education level and healthcare factors such as the number of follow-up visits or medical levels performed by related workers are prior to those in the whole country. Although immunological criteria for treatment failure is less sensitive and specific than virological criteria, the failure rate of this study was fairly reliable, with median times of 11 CD4 cell counts per patient during follow-up compared to only three times in a previous study. ${ }^{12}$ Further analysis of risk factors indicated that the patients who were most immunosuppressed and had higher WHO stages at 
Table 2 Rates and risk factors for virological and immunological failure by cox proportional hazards regression

\begin{tabular}{|c|c|c|c|c|c|c|c|c|}
\hline \multirow[b]{2}{*}{ Characteristic } & \multicolumn{4}{|c|}{ Virological failure } & \multicolumn{4}{|c|}{ Immunological failure } \\
\hline & $\begin{array}{l}\text { Failure } \\
\text { patients } \\
\mathbf{N}(\%)\end{array}$ & $\begin{array}{l}\text { Rate per } 100 \\
\text { Patient-Years }\end{array}$ & HR $(95 \% \mathrm{Cl})$ & AHR (95\% Cl) & $\begin{array}{l}\text { Failure } \\
\text { patients } \\
\mathrm{N}(\%)\end{array}$ & $\begin{array}{l}\text { Rate per } 100 \\
\text { Patient-Years }\end{array}$ & HR (95\% Cl) & AHR (95\% Cl) \\
\hline \multicolumn{9}{|l|}{ Age, years } \\
\hline $18-30$ & $104(13.0)$ & 6.9 & 1.00 & - & $135(16.9)$ & 9.3 & 1.00 & 1.00 \\
\hline $31-50$ & $165(13.7)$ & 7.4 & 1.06 (0.83 to 1.35$)$ & - & $217(18.1)$ & 9.7 & 1.05 (0.85 to 1.31$)$ & $0.92(0.74$ to 1.15$)$ \\
\hline$>50$ & 23 (13.5) & 6.5 & 0.97 (0.62 to 1.53$)$ & - & 48 (28.2) & 15.4 & 1.67 (1.20 to 2.32$)$ & 1.42 (1.01 to 2.02$)$ \\
\hline \multicolumn{9}{|l|}{ Sex } \\
\hline Male & $225(13.2)$ & 7.5 & 1.00 & - & $307(18.1)$ & 10.5 & 1.00 & - \\
\hline Female & $67(14.2)$ & 6.2 & 0.91 (0.69 to 1.20$)$ & - & $93(19.7)$ & 8.7 & $0.93(0.74$ to 1.18$)$ & - \\
\hline \multicolumn{9}{|l|}{ Infection route } \\
\hline Heterosexual & $147(13.1)$ & 6.6 & 1.00 & 1.00 & $219(19.5)$ & 9.9 & 1.00 & 1.00 \\
\hline Homosexual & 106 (11.9) & 6.7 & $0.98(0.76$ to 1.25$)$ & 1.03 (0.81 to 1.32$)$ & $138(15.5)$ & 9.5 & 0.88 (0.71 to 1.09$)$ & $1.04(0.83$ to 1.31$)$ \\
\hline $\begin{array}{l}\text { Intravenous drug } \\
\text { use }\end{array}$ & $16(28.1)$ & 15.0 & 2.27 (1.35 to 3.80$)$ & 2.09 (1.05 to 4.17$)$ & $18(31.6)$ & 14.1 & 1.62 (1.00 to 2.63$)$ & 1.52 (0.93 to 2.49$)$ \\
\hline Others & $23(23.7)$ & 11.8 & 1.81 (1.16 to 2.80$)$ & 1.48 (0.60 to 3.66$)$ & $25(25.7)$ & 12.8 & $1.36(0.90$ to 2.06$)$ & 1.16 (0.65 to 2.10$)$ \\
\hline \multicolumn{9}{|c|}{ Baseline CD4 count, cells $/ \mathrm{mm}^{3}$} \\
\hline $0-49$ & $61(14.4)$ & 6.6 & 1.00 & - & $132(32.2)$ & 14.3 & 1.00 & 1.00 \\
\hline $50-99$ & $46(18.3)$ & 9.0 & 1.34 (0.91 to 1.96$)$ & - & $42(16.7)$ & 7.7 & $0.53(0.37$ to 0.74$)$ & 0.46 (0.32 to 0.66$)$ \\
\hline $100-199$ & $86(13.9)$ & 7.2 & $1.04(0.75$ to 1.45$)$ & - & $103(16.6)$ & 9.2 & $0.58(0.45$ to 0.75$)$ & 0.53 (0.41 to 0.70$)$ \\
\hline 200-349 & $60(8.5)$ & 5.2 & $0.68(0.47$ to 1.01$)$ & - & $91(12.9)$ & 9.4 & 0.52 (0.39 to 0.67$)$ & 0.96 (0.67 to 1.38$)$ \\
\hline$\geq 350$ & 39 (22.9) & 12.5 & 1.08 (0.68 to 2.06$)$ & - & $28(16.5)$ & 6.8 & $0.53(0.35$ to 0.81$)$ & $0.68(0.44$ to 1.04$)$ \\
\hline \multicolumn{9}{|c|}{ Baseline viral load, copies/mL } \\
\hline$<10000$ & $20(9.7)$ & 4.7 & 1.00 & 1.00 & $44(21.3)$ & 11.4 & 1.00 & - \\
\hline $10000-49999$ & $18(5.8)$ & 2.7 & $0.58(0.31$ to 1.10$)$ & 0.54 (0.28 to 1.02$)$ & $49(15.7)$ & 8.3 & $0.72(0.48$ to 1.08$)$ & - \\
\hline $50000-99999$ & $13(6.8)$ & 3.5 & 0.73 (0.36 to 1.46$)$ & 0.65 (0.34 to 1.35$)$ & $20(10.5)$ & 5.8 & 0.68 (0.45 to 1.02$)$ & - \\
\hline 100 000-999999 & $112(11.6)$ & 7.3 & $1.36(0.85$ to 2.19$)$ & $1.19(0.73$ to 1.94$)$ & $152(15.7)$ & 10.4 & $0.80(0.57$ to 1.12$)$ & - \\
\hline$\geq 1000000$ & 40 (18.6) & 11.4 & 2.61 (1.52 to 4.48$)$ & 2.19 (1.25 to 3.84$)$ & $54(25.1)$ & 15.5 & $1.50(0.98$ to 2.24$)$ & - \\
\hline \multicolumn{9}{|c|}{ Baseline WHO stage } \\
\hline 1 & $17(7.8)$ & 5.1 & 1.00 & 1.00 & $24(11.1)$ & 7.7 & 1.00 & 1.00 \\
\hline II & $97(11.1)$ & 6.0 & 1.27 (0.76 to 2.13 ) & 1.86 (0.80 to 4.33$)$ & $115(13.2)$ & 7.3 & 1.09 (0.70 to 1.69$)$ & 0.96 (0.61 to 1.52$)$ \\
\hline Ш & $31(8.7)$ & 3.9 & 0.88 (0.49 to 1.59$)$ & 0.74 (0.27 to 2.07$)$ & $88(24.6)$ & 11.4 & 1.77 (1.13 to 2.78$)$ & 1.69 (1.07 to 2.69$)$ \\
\hline IV & $147(20.3)$ & 10.8 & 2.36 (1.43 to 3.90$)$ & 4.61 (2.01 to 10.57$)$ & $173(23.8)$ & 12.9 & 1.92 (1.25 to 2.94$)$ & 2.15 (1.38 to 3.34$)$ \\
\hline
\end{tabular}


A

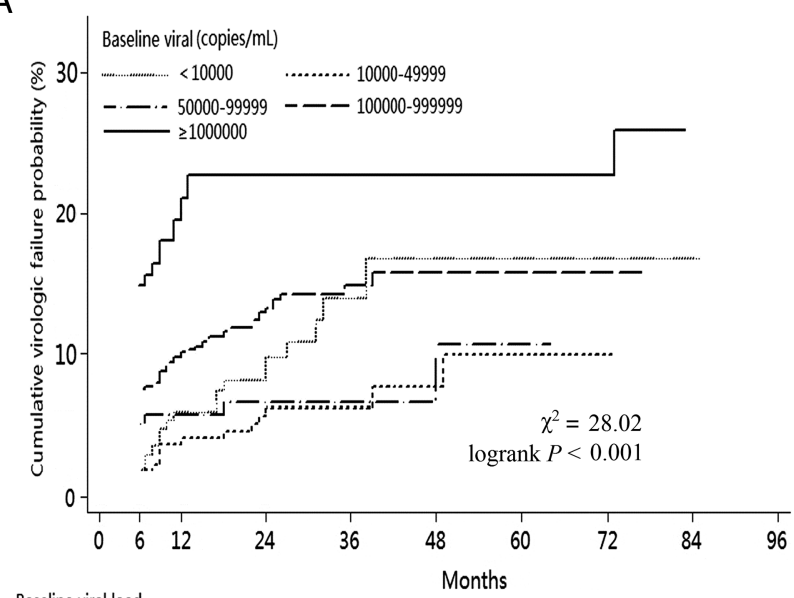

Baseline viral load (copies/mL)

$<10000 \quad 207 \quad 150$

10000-49999 $312 \quad 241$

50000-99999 191136

100000-999999969 619

$\geq 1000000 \quad 215 \quad 53$

C

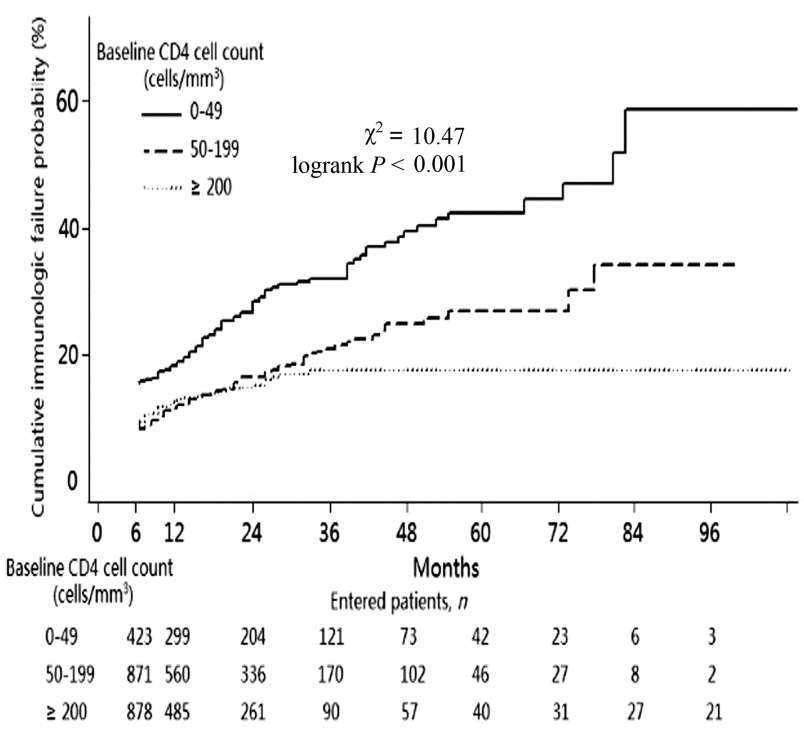

B

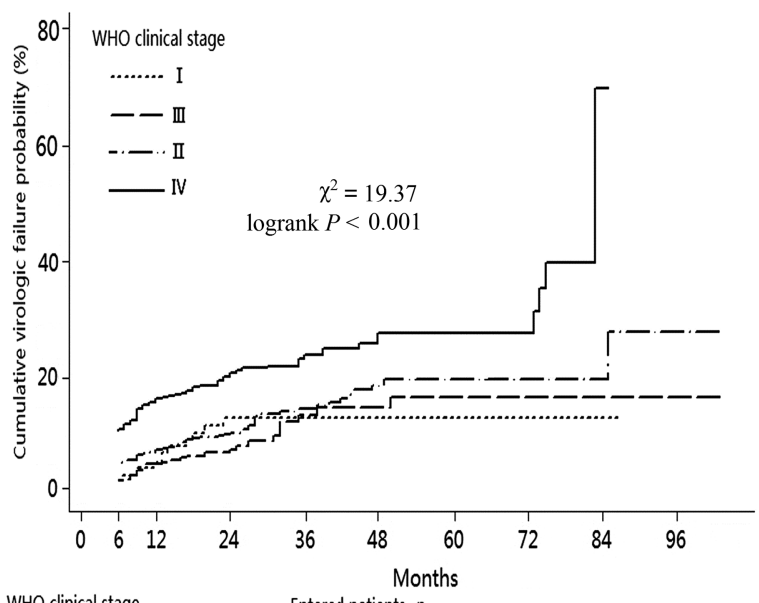

WHO clinical stage

$\begin{array}{ccccccccc}\text { I } & 217113 & 67 & 29 & 14 & 9 & 5 & 3 & 0 \\ \text { III } & 871575 & 352 & 164 & 87 & 36 & 72 & 11 & 7 \\ \text { II } & 358274 & 155 & 68 & 53 & 42 & 24 & 10 & 7 \\ \text { IV } & 726460 & 290 & 140 & 88 & 35 & 21 & 2 & 0\end{array}$

D

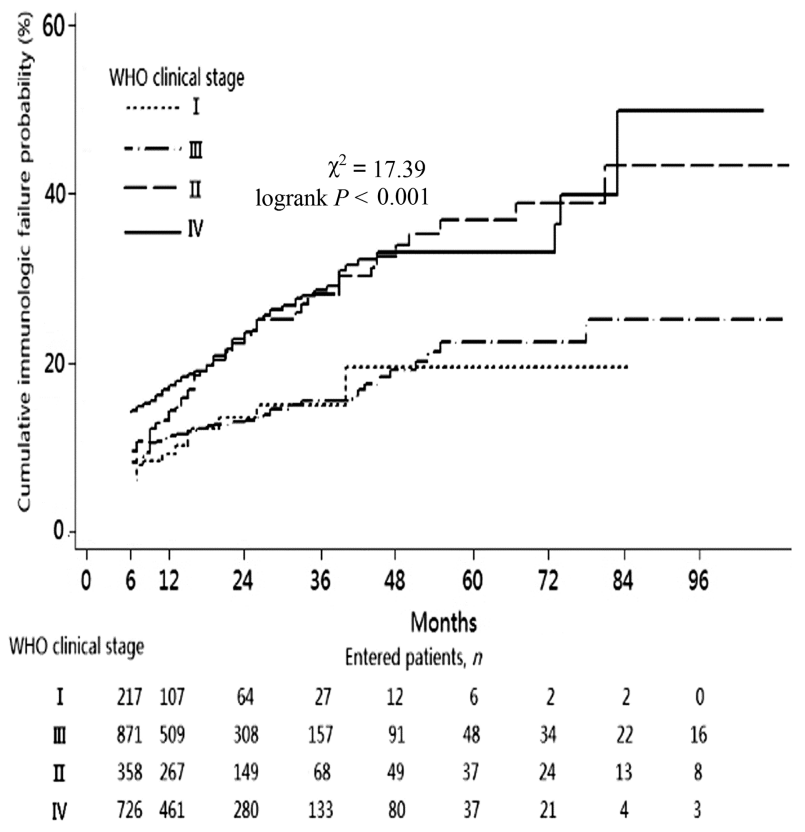

Figure 1 Outcome of virological and immunological treatment. (A) Cumulative virological failure rate, stratified by baseline viral load. (B) Cumulative virological failure rate, stratified by baseline WHO clinical stage. (C) Cumulative immunological failure rate, stratified by baseline CD4 cell count. (D) Cumulative immunological failure rate, stratified by baseline WHO clinical stage.

baseline tended to experience immunological failure, similar to other studies. ${ }^{11}{ }^{22}$ Meanwhile, there was a sharp contrast between the CD4 cell count responses of the immunological treatment failure and success cohorts, and among groups with different baseline CD4 cell counts. Thus, baseline CD4 cell counts and WHO stages may predict immunological outcomes, which may be useful for other resource-limited settings.

In our study, virological outcomes were consistent with those of others in which the virological failure rate of
ART in developing countries worldwide ranged from $10 \%$ to $28 \%$ at 6 months, $14 \%$ to $50 \%$ at 12 months and $29 \%$ at $>24$ months. ${ }^{23-26}$ In multivariate model, virological outcome was mainly associated with baseline viral load and WHO stage, similar to other studies. ${ }^{26}{ }^{27}$ Owing to constraints of costs and technology, monitoring plasma viral load, a standard practice in developed countries, was not recommended in low-income countries. Viral load testing could be of increasing importance in guiding clinical decisions on how to perfect the duration of the first- 

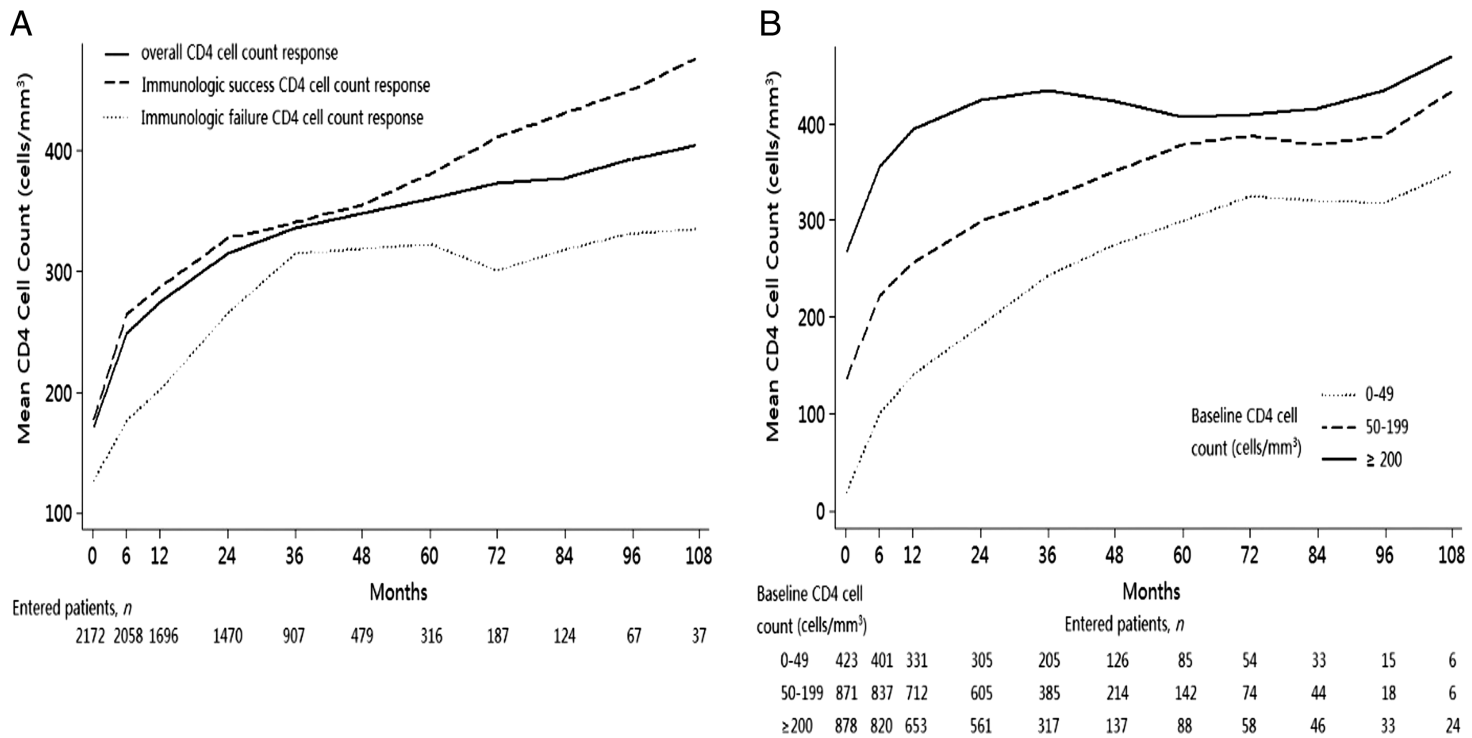

Figure 2 CD4 cell count response after antiretroviral treatment (ART) initiation. (A) Median (IQR) CD4 cell count increase from ART initiation, stratified by immunological success and failure. (B) Median (IQR) CD4 cell count increase from ART initiation, stratified by baseline CD4 cell count.

line treatment regimen and on when to divert to secondline treatment. Previous study clinical and immunological criteria were poor predictors of virological outcome. Treatment failure based only on clinical and immunological factors may lead to some patients switching to second-line regimen at an inappropriate time, which may cause higher mortality and drug resistance. ${ }^{28} 29$

Our study has several limitations. First, observational study had potential inherent biases. Data were collected by healthcare providers who had different opinions facing the same situation. In addition, it was inevitable that missing data existed in a cohort study. However, the data were a reflection of treatment realities. Second, medication adherence associated with treatment failure was hardly measured. ${ }^{30}$ Although the number of missed doses in the previous 7 days was used to evaluate medication adherence, the data were inaccurate and vastly missing during the follow-up. Finally, in this study, opportunistic infections data were also excluded for further analysis. With the difficulty in definitively diagnosing opportunistic infections, it was not precise in using easily identified signs and symptoms as a proxy.

In summary, through this 10-year study of 2172 ART adults receiving treatment, we find that the immunological and virological failure rates were slightly high, but the mortality rate was quite low. The outcomes of treatment and potential risk factors may provide important information for clinicians and policymakers in the region as they begin to evaluate and plan for the future needs of their own rapidly expanding programmes.

Contributors $\mathrm{PH}, \mathrm{ZP}$ and $\mathrm{HZ}$ performed the experiments. PH, JT and WM analysed the data. JT and YL contributed reagents/materials/analysis tools. $\mathrm{PH}$ and JT were involved in writing of the manuscript. ZP and RY conceived and designed the whole research, provided the funding and were responsible for the project. NW, ZP and RY designed the epidemiological researches.
Funding This work was supported in part by the Natural Science Foundation of China (grant numbers 81001288, 11171268), National S\&T Major Project Foundation of China (grant number 2012ZX10001-001), Priority Academic Programme Development of Jiangsu Higher Education Institutions (PAPD).

Competing interests None declared.

Patient consent Obtained.

Ethics approval Institutional Review Board of the Nanjing Medical University. Provenance and peer review Not commissioned; externally peer reviewed.

Data sharing statement No additional data are available.

Open Access This is an Open Access article distributed in accordance with the Creative Commons Attribution Non Commercial (CC BY-NC 4.0) license, which permits others to distribute, remix, adapt, build upon this work noncommercially, and license their derivative works on different terms, provided the original work is properly cited and the use is non-commercial. See: http:// creativecommons.org/licenses/by-nc/4.0/

\section{REFERENCES}

1. Wang N, Wang L, Wu Z, et al. Estimating the number of people living with HIV/AIDS in China: 2003-09. Int J Epidemiol 2010;39: ii21-8.

2. Joint Assessment of HIV/AIDS Prevention, Treatment and Care in China (2013). State Council AIDS Working Committee Office, UN Theme Group on AIDS in China, China Ministry of Health, Beijing. 2013

3. Zhang F, Haberer J, Wang Y, et al. The Chinese free antiretroviral treatment program: challenges and responses. AIDS 2007;21: S143-8.

4. Wu Z, Sullivan S, Wang Y, et al. Evolution of China's response to HIV/AIDS. Lancet 2007;369:679-90.

5. Wong K, Chan K. HAART for HIV in China-much achieved, more to be done. Lancet Infect Dis 2011:11:491-2.

6. Zhang F, Dou Z, Ma Y, et al. Effect of earlier initiation of antiretroviral treatment and increased treatment coverage on HIV-related mortality in China: a national observational cohort study. Lancet Infect Dis 2011;11:516-24.

7. Yin $\mathrm{W}$, Hao $\mathrm{Y}$, Sun $\mathrm{X}$, et al. Scaling up the national methadone maintenance treatment program in China: achievements and challenges. Int J Epidemiol 2010;39:ii29-37.

8. Lu L, Jia M, Ma Y, et al. The changing face of HIV in China. Nature 2008;455:609-11. 
9. Stringer J, Zulu I, Levy J, et al. Rapid scale-up of antiretroviral therapy at primary care sites in Zambia: feasibility and early outcomes. JAMA 2006;296:782-93.

10. Ferradini $L$, Jeannin A, Pinoges $L$, et al. Scaling up of highly active antiretroviral therapy in a rural district of Malawi: an effectiveness assessment. Lancet 2006;367:1335-42.

11. Boulle A, Van Cutsem G, Hilderbrand K, et al. Seven-year experience of a primary care antiretroviral treatment programme in Khayelitsha, South Africa. AIDS 2010;24:563-72.

12. Zhang F, Dou Z, Ma Y, et al. Five-year outcomes of the China National Free Antiretroviral Treatment Program. Ann Intern Med 2009;151:241-51.

13. Bussmann $\mathrm{H}$, Wester $\mathrm{C}$, Ndwapi $\mathrm{N}$, et al. Five-year outcomes of initial patients treated in Botswana's National Antiretroviral Treatment Program. AIDS 2008;22:2303-11.

14. Mermin J, Were W, Ekwaru J, et al. Mortality in HIV-infected Ugandan adults receiving antiretroviral treatment and survival of their HIV-uninfected children: a prospective cohort study. Lancet 2008;371:752-9.

15. Ferradini L, Laureillard D, Prak N, et al. Positive outcomes of HAART at 24 months in HIV-infected patients in Cambodia. AIDS 2007;21:2293-301.

16. Li N, Wang Z, Sun D, et al. HIV among plasma donors and other high-risk groups in Henan, China. J Acquir Immune Defic Syndr 2010;53:S41-7.

17. Zhao Y, Sun X, He Y, et al. Progress of the National Pediatric Free Antiretroviral Therapy program in China. AIDS Care 2010;22:1182-8.

18. Gilks C, Crowley S, Ekpini R, et al. The WHO public-health approach to antiretroviral treatment against HIV in resource-limited settings. Lancet 2006;368:505-10.

19. Zhang F, Pan J, Yu L, et al. Current progress of China's free ART program. Cell Res 2005;15:877-82.

20. World Health Organization. Antiretroviral therapy for HIV infection in adults and adolescents: recommendations for a public health approach: 2010 revision. Geneva: World Health Organization, 2010.
21. Ivers L, Kendrick D, Doucette K. Efficacy of antiretroviral therapy programs in resource-poor settings: a meta-analysis of the published literature. Clin Infect Dis 2005;41:217-24.

22. Coetzee D, Hildebrand K, Boulle A, et al. Outcomes after two years of providing antiretroviral treatment in Khayelitsha, South Africa. AIDS 2004;18:887-95.

23. Boileau $\mathrm{C}$, Nguyen $\mathrm{V}$, Sylla $\mathrm{K}$, et al. Low prevalence of detectable HIV plasma viremia in patients treated with antiretroviral therapy in Burkina Faso and Mali. J Acquir Immune Defic Syndr 2008;48:476-84.

24. Fielding K, Charalambous S, Stenson A, et al. Risk factors for poor virological outcome at 12 months in a workplace-based antiretroviral therapy programme in South Africa: a cohort study. BMC Infect Dis 2008;8:93

25. Tuboi S, Brinkhof M, Egger M, et al. Discordant responses to potent antiretroviral treatment in previously naive HIV-1-infected adults initiating treatment in resource-constrained countries: the antiretroviral therapy in low-income countries (ART-LINC) collaboration. J Acquir Immune Defic Syndr 2007;45:52-9.

26. Ma Y, Zhao D, Yu L, et al. Predictors of virologic failure in HIV-1-infected adults receiving first-line antiretroviral therapy in 8 provinces in China. Clin Infect Dis 2010;50:264-71.

27. Djomand G, Roels $\mathrm{T}$, Ellerbrock $\mathrm{T}$, et al. Virologic and immunologic outcomes and programmatic challenges of an antiretroviral treatment pilot project in Abidjan, Cote d'Ivoire. AIDS 2003;17:S5-15.

28. Kantor R, Diero L, Delong A, et al. Misclassification of first-line antiretroviral treatment failure based on immunological monitoring of HIV infection in resource-limited settings. Clin Infect Dis 2009;49:454-62.

29. Cozzi-Lepri A, Phillips A, Ruiz L, et al. Evolution of drug resistance in HIV-infected patients remaining on a virologically failing combination antiretroviral therapy regimen. AIDS 2007;21:721-32.

30. Lima V, Harrigan R, Bangsberg D, et al. The combined effect of modern highly active antiretroviral therapy regimens and adherence on mortality over time. J Acquir Immune Defic Syndr 2009;50:529-36. 